\title{
The epidemiology of eating disorders: genetic, environmental, and societal factors
}

This article was published in the following Dove Press journal:

Clinical Epidemiology

17 February 2014

Number of times this article has been viewed

\author{
Deborah Mitchison' \\ Phillipa J Hay ${ }^{2,3}$ \\ 'School of Medicine, University \\ of Western Sydney, Sydney, NSW, \\ Australia; ${ }^{2}$ Centre for Health \\ Research, School of Medicine, \\ University of Western Sydney, Sydney, \\ NSW, Australia; ${ }^{3}$ School of Medicine, \\ James Cook University, Townsville \\ City, QLD, Australia
}

Background: The aim of this review was to summarize the literature to date regarding the sociodemographic, environmental, and genetic correlates of eating disorders (EDs) in adults.

Method: A keyword search was entered into Scopus (SciVerse, Elsevier) to identify relevant articles published in English up until June 2013. Articles were assessed against a range of a priori inclusion and exclusion criteria.

Results: A total of 149 full-text articles were found to be eligible for the review and included 86 articles with data on sociodemographic correlates, 57 on environmental correlates, and 13 on genetic correlates. Female sex, younger age, sexual and physical abuse, participation in esthetic or weight-oriented sports, and heritability were found to be most consistently associated with higher ED prevalence and incidence. Conversely, ethnicity, socioeconomic status, education, and urbanicity did not appear to have strong associations with ED epidemiology.

Conclusion: More community-based research, with an equal representation of males, needs to be conducted to confirm the current findings and provide evidence for emerging factors that may be related to EDs.

Keywords: demographic, environment, abuse, prevalence, socioeconomic status, heritability

\section{Background}

The eating disorders (EDs), including anorexia nervosa (AN), bulimia nervosa (BN), binge eating disorder (BED), and other specified and unspecified EDs (previously known as ED not otherwise specified or EDNOS) constitute a group of disorders involving disturbed body image coupled with eating and/or weight loss behaviors ${ }^{1}$ that cause severe distress and impairment to quality of life. ${ }^{2}$ The burden of these disorders on the community and health care system is also high. A German study, for example, has found that in the year 1998, the cost of lost productivity in AN due to an inability to work was $€ 130.5$ million, while inpatient treatment costs alone were $€ 62.9$ million. ${ }^{3}$ The current figures, especially those taking into account outpatient care across the EDs are expected to be much higher; however, an updated study is yet to be conducted to verify this.

The ED field lags behind other psychiatric fields (eg, mood, ${ }^{4}$ anxiety, ${ }^{5}$ and psychotic $^{6}$ disorders) in the progress of epidemiological research. Reasons for this may include the fact that ED research is smaller and newer, and compared with disorders considered more "mainstream," EDs have been excluded from some large national surveys. ${ }^{7}$ Further, the relatively low prevalence of EDs (particularly AN) requires the recruitment and diagnostic assessment of particularly large population samples, a complex and costly task.
Correspondence: Phillipa J Hay University of Western Sydney, Locked Bag 1797, Penrith, NSW 275I, Australia

Tel +6I 246203838

Fax +6| $24620389 \mid$

Email p.hay@uws.edu.au 
In a review published in 2006, $\mathrm{Hoek}^{8}$ found prevalence estimates were about $0.3 \%$ for $\mathrm{AN}$ and $1.0 \%$ for $\mathrm{BN}$ in young females, but that this ranged considerably between studies. The reasons for variation in the estimates is likely multifactorial and probably includes factors such as the year of assessment, the population group being sampled, the assessment methodology used (from structured interview to self-report), and the diagnostic classification system and version that is imposed (eg, the Diagnostic and Statistical Manual for Mental Disorders [DSM] ${ }^{1}$ or the International Classification of Diseases [ICD] ${ }^{9}$ ).

The majority of studies that assess correlates of EDs are based on clinical samples. However, people with EDs who receive treatment are a select group with particular characteristics. Indeed, we know that the vast majority of people in the community with EDs do not seek or receive treatment, ${ }^{10-13}$ and particularly underrepresented groups may include males, and those who are older, poorer, or more remote-dwelling. ${ }^{14}$ Thus, while clinical studies may be representative of a treatment-receiving population, they are likely not representative of the wider ED population. A problem that may arise from this is that any factors found to be significantly correlated with EDs in clinical studies may be artificially so, especially if the impact of characteristics particular to a treatment-receiving group - such as being younger, female, or more motivated - are not carefully partialed out.

The number of published population and communitybased studies is gradually increasing in the ED field, and these are adding to an evidence-base that will help us to more accurately characterize EDs in future. For instance, this evidence-base has already aided our shifting away from the long-held perception that EDs are the domain of the wealthy, White, young female toward the notion that disordered eating and body image disturbance are experienced by males and females ${ }^{15,16}$ of all ages ${ }^{17}$ and ethnicities ${ }^{18,19}$ and who live in both developed and developing countries. ${ }^{20,21}$ Nonclinical studies have also been published that examine the genetic and environmental influences on EDs. A summary of what these studies have found thus far is overdue and would provide a representative and generalizable account of factors that are related to EDs in the community - an endeavor, as far as we are aware, has not been previously attempted.

\section{Aims}

The aim of the current review was thus to identify and appraise the published literature regarding the sociodemographic, environmental, and genetic correlates of ED prevalence and/or incidence in the community. Other correlates (eg, psychological, functional impairment, and comorbidities) were considered outside the scope of the current paper. Beyond providing a review of the progress of epidemiological research in the ED field, this review also aimed to highlight current gaps in knowledge and to provide directions for further research.

\section{Methods}

The methodology used was based on the PRISMA Statement. ${ }^{22}$

\section{Inclusion and exclusion criteria}

The set of inclusion and exclusion criteria developed for the current review is summarized in Table 1. We were specifically interested in articles that reported on the epidemiology of diagnostic entities (ie, not specific features or broad "disordered eating" or "body image disturbance"); however, we included findings related to subclinical syndromes (eg, subclinical DSM-IV AN, which excludes the amenorrhea criterion, which may now meet DSM-5 criteria for AN or atypical AN) and also studies with varying methodology used to classify diagnoses. For instance, studies that used earlier versions of the DSM and ICD were permitted, as well as studies that used self-report of EDs. Articles based on university samples were excluded (except where the university setting was particular to the correlate under investigation), as such samples were not considered sociodemographically representative of the broader community, particularly in terms of age, socioeconomic status, and educational achievement. Further, the prevalence of disordered eating may be higher in university compared with

Table I Selection criteria for the review

\begin{tabular}{ll}
\hline Category & Criteria \\
\hline Population & - Any human study of the general population or \\
Assessment of & - Any recognizable eating disorder \\
eating disorders & - Assessed against current or past classification \\
Correlates & schemes or by self-report \\
- Epidemiological comparisons made based on & sociodemographic, environmental, and/or \\
Specific exclusions & - Renetic factors \\
& Reports on the epidemiology of non-diagnostic \\
- University samples, where the university \\
environment is not specifically being assessed \\
as a correlate \\
- Clinical samples \\
- Samples derived from one school only \\
- Samples derived from private schools only
\end{tabular}


community samples. ${ }^{23}$ For similar reasons, articles were also excluded if they included sampling from only one school or from private schools only.

\section{Literature search strategy}

We searched Scopus (SciVerse, Elsevier) using the keyword search function and entering the following algorithm: ["anorexia nervosa" OR "bulimia nervosa" OR "binge eating disorder" OR "eating disorder"] AND ["community" OR "population" OR "epidemiology" OR "epidemiological” OR “prevalence” OR “incidence” OR “risk”]. Scopus includes articles dated as far back as 1966, and we included all articles to June 2013 in our search. Titles and abstracts were systematically reviewed against the a priori criteria (see Table 1), and those that did not meet eligibility were excluded. Further review of the remaining articles involved full-text inspection, which further reduced the number of articles to be included in the review. Reasons for exclusion were recorded throughout the process. See Figure 1 for a flowchart of the article selection and culling process.

\section{Data extraction}

All data were extracted by one author (DM). The second author, $\mathrm{PH}$, acted as consultant where decisions on inclusion and exclusion were unclear on first review. Data were entered into an Excel $^{\circledR}$ (Microsoft Corporation, Redmond, WA, USA) spreadsheet, from which summary tables were derived. Data extracted included sample size, study wave, response rate, population, year of data collection, diagnostic strategy, country, age range (or where range not available, measures of central tendency), sex ratio, design (cross-sectional or longitudinal), prevalence and/or incidence data, correlates investigated, and findings. This data is summarized in the Supplementary materials.

\section{Assessment of risk of bias used in this review}

We anticipated or preempted that varying methods of diagnostic assessment used across studies could present a risk of bias in this review. To assess the extent of this risk, we established a hierarchy that included six levels $(1=$ most rigorous; $6=$ least rigorous) to cover the methods used by the studies:

\section{Level I}

Level 1 included studies using a structured clinical interview designed to assess either EDs specifically (eg, the Eating Disorder Examination ${ }^{24}$ ) or a range of psychiatric disorders

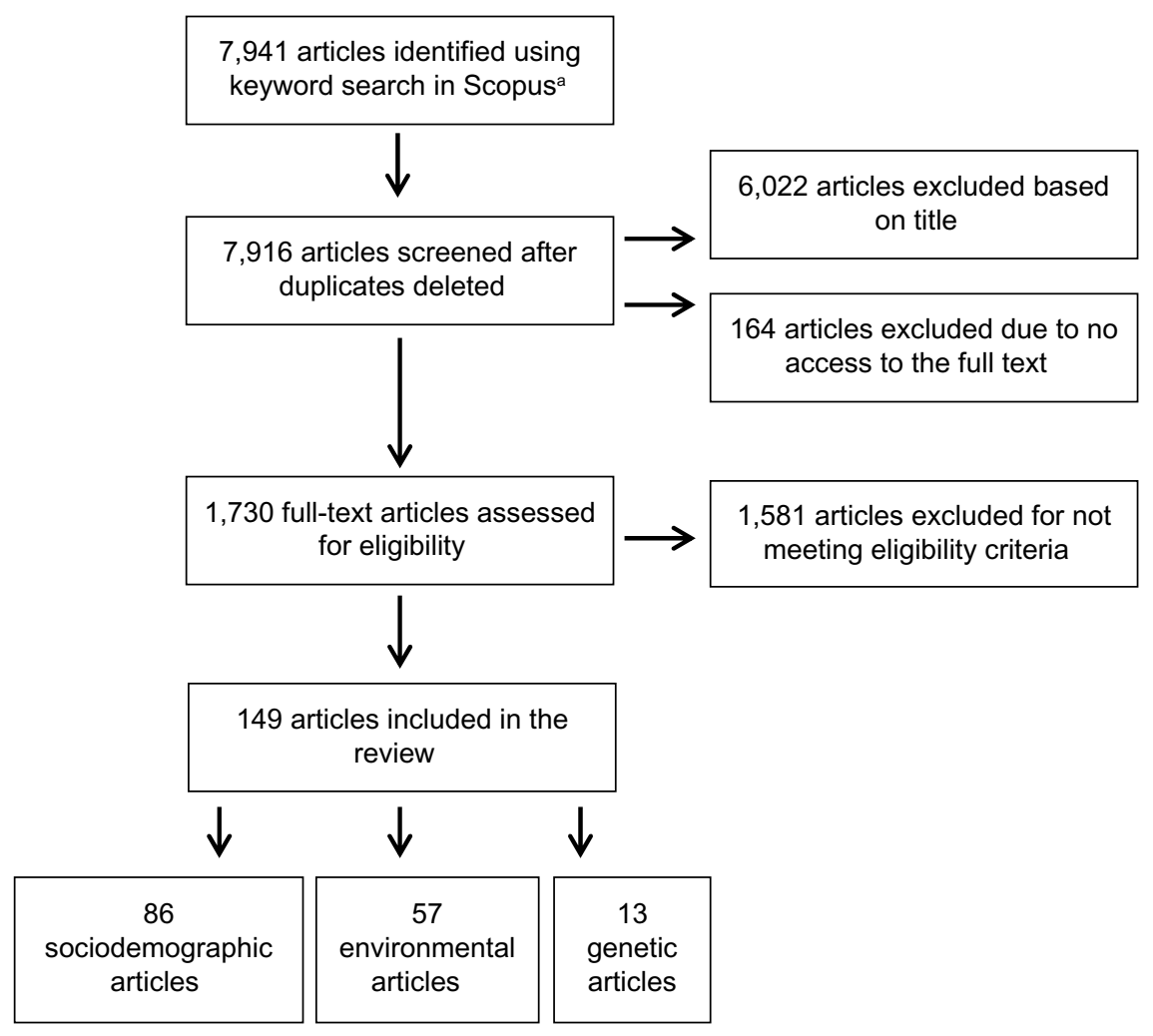

Figure I Flowchart depicting the process of article selection for the review.

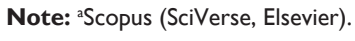


including EDs (eg, the Structured Clinical Interview for DSM-IV Axis I Disorders ${ }^{25}$ ) based on criteria set out in either the DSM or ICD classification schemes.

\section{Level 2}

Level 2 included studies using an unstructured clinical interview conducted by an expert, with the aim to establish the presence of an ED diagnosis according to DSM or ICD criteria.

\section{Level 3}

Level 3 included studies using a standardized questionnaire specifically designed to assess ED diagnosis according to DSM or ICD criteria (eg, the Survey for Eating Disorders $\left.{ }^{26}\right)$.

\section{Level 4}

Level 4 included studies using an unstandardized questionnaire, designed by the authors of the study (or another study) to detect ED diagnoses according to DSM or ICD criteria, usually not empirically tested.

\section{Level 5}

Level 5 included studies using a standardized questionnaire designed to assess ED psychopathology but not ED diagnosis, according to established criteria (eg, the Eating Disorder Examination Questionnaire ${ }^{27}$ ).

\section{Level 6}

Level 6 included studies using the self-report (or selfidentification) of an ED either through a questionnaire or during an interview.

\section{Data summarizing strategy}

Studies included in this review either ran a number of separate analyses to assess the association between a correlate and the epidemiology of different ED diagnoses (eg, AN, $\mathrm{BN}$, and BED separately), or conducted one analysis with all ED diagnoses grouped together. Thus, studies could include both null and significant effects related to the one correlate, if for instance the correlate was associated with one diagnosis (eg, BED) but not with another (eg, BN). To deal with this, we tallied the findings according to the number of analyses conducted rather than the number of studies finding a specific result. Studies also sometimes reported both a null effect and a significant effect for an association between a correlate and the epidemiology of a particular $\mathrm{ED}$, if for instance an association was found with the point prevalence of the ED, but not the lifetime prevalence. In this instance, we documented both an effect and a null effect for the correlate. Owing to the large number of articles identified that assessed sociodemographic and environmental correlates of EDs, Tables 2 and 3 provide a briefer summary of the findings, and do not separate findings according to specific ED diagnoses. Diagnostic level findings are available at the study-level in the Supplementary materials. An across-studies summary of diagnostic findings is also available from the authors upon request.

\section{Results}

\section{Articles included and excluded}

We identified 149 articles that met eligibility for the current review. Eighty-six of these reported on sociodemographic correlates, 57 on environmental correlates, and 13 on genetic correlates of ED epidemiology. Seven of the 149 articles reported on both sociodemographic and environmental correlates; thus, the sum of the number of articles reporting each type of correlate $(86+57+13=156)$ exceeds the total $N$ of eligible articles. Of the 1,730 full-text articles systematically reviewed for eligibility, 1,581 were excluded. The most common reasons for exclusion were: reporting on ED features rather than clinical or subclinical diagnostic entities $(\mathrm{n}=682)$, and being based on clinical $(\mathrm{n}=291)$ or university $(\mathrm{n}=147)$ samples.

The publication dates for included articles ranged from 1985 to 2013. Based on the articles that reported the following information: recruitment dates for study samples ranged from 1975 to 2008; sample sizes ranged from $n=45$ to $n=48,378$; and the average proportion of female participants was $79 \%$. Participants were recruited from 30 different countries: Australia, Belgium, Brazil, Canada, the People's Republic of China, Colombia, Denmark, England, Estonia, Finland, France, Germany, Greece, Hungary, Iran, Israel, Italy, Jordan, Kenya, Mexico, New Zealand, the Netherlands, Northern Ireland, Norway, Portugal, Romania, Sweden, Turkey, the United Kingdom, and the United States. ED diagnoses assessed across the studies included AN, BN, BED, EDNOS, subclinical AN, subclinical BN, subclinical BED, and night eating syndrome. A range of methods were used for diagnostic assessment. Most often a formal structured clinical interview was used; however, unstructured clinical interview, diagnostic questionnaires, and self-report (rarely) were also used. Owing to the range in years of participant recruitment, the version of the classification schemes imposed also ranged from the DSM-III to the DSM-IV-TR. For full details on the sample size, response rate, study design, diagnostic assessment, sex 
Table 2 Sociodemographic correlates of eating disorder epidemiology

\begin{tabular}{|c|c|c|c|c|}
\hline Correlate & n studies & $\begin{array}{l}n \text { analyses with } \\
\text { null effects }\end{array}$ & $\begin{array}{l}n \text { analyses } \\
\text { with an effect }\end{array}$ & Effect(s) found ( $n$ analyses with the effect) \\
\hline Age & 41 & 33 & 41 & $\begin{array}{l}\text { Younger (18); older (9); specific age group: } 12-15,15-16 \text {, } \\
16-18,<20,>18,<30,18-34,25-44,<45 \text { years }(12)\end{array}$ \\
\hline Sex & 39 & 34 & 58 & Female sex (58) \\
\hline Ethnicity/race & 18 & 31 & 16 & $\begin{array}{l}\text { White (3), Black (3), Romanian (3), Hispanic (3), Maori or } \\
\text { Pacific Islander (2), Asian (I), minority (I) }\end{array}$ \\
\hline Education level & 16 & 15 & 8 & $\begin{array}{l}\text { Lower educational attainment (4); higher educational } \\
\text { attainment (4) }\end{array}$ \\
\hline Socioeconomic status & 10 & 16 & 6 & Lower socioeconomic status (4); higher socioeconomic status (2) \\
\hline Urbanicity & 9 & 12 & 5 & Urban residency (4); regional residency $(\mathrm{I})$ \\
\hline Marital status & 9 & 10 & 2 & Single (2) \\
\hline Parental education & 8 & 11 & 3 & Higher parental education ( 3 ) \\
\hline Parental marital status & 6 & 7 & 2 & Parents separated or widowed (2) \\
\hline Parental occupation & 6 & 9 & 4 & At-home mother (2); father who works in private business (2) \\
\hline Menarche/oigarche timing & 4 & 6 & 3 & Earlier commencement of menarche or oigarche (3) \\
\hline Student status & 4 & 2 & 5 & Current student (5) \\
\hline Occupational status & 4 & 4 & 1 & Unemployed (I) \\
\hline Country of birth & 3 & 4 & 0 & $\mathrm{~N} / \mathrm{A}$ \\
\hline Sexual orientation & 3 & 8 & 3 & Homosexuality or bisexuality (3) \\
\hline Number of siblings & 2 & I & 2 & Has siblings (I); only child (I) \\
\hline Child status & 2 & I & 1 & Parent to more than one child (I) \\
\hline Living arrangement & 2 & I & I & Living with a single parent $(\mathrm{I})$ \\
\hline Birth order & 2 & 5 & 0 & $\mathrm{~N} / \mathrm{A}$ \\
\hline Parental immigrant status & 2 & 7 & 3 & Mother, father, or both parents not being immigrants (3) \\
\hline Country of residence & I & I & 1 & USA (I) \\
\hline Migration status & I & 2 & 1 & Not being a migrant $(I)$ \\
\hline Gender identity & I & 0 & I & Female gender-type identity $(I)$ \\
\hline Parental age & 1 & 0 & I & Higher paternal age at birth (I) \\
\hline Family composition & I & I & 0 & $N / A$ \\
\hline Years spent in USA & I & 1 & I & More years in the USA (I) \\
\hline Immigrant generation status & I & I & 0 & $\mathrm{~N} / \mathrm{A}$ \\
\hline Anglo orientation & I & 0 & 1 & Greater anglo orientation (I) \\
\hline Languages & I & 0 & I & Being monolingual (I) \\
\hline Acculturation & I & I & I & Greater acculturation (I) \\
\hline
\end{tabular}

Abbreviation: N/A, not applicable.

ratio, age range, and nationality of the 149 articles, please refer to the supplementary Tables provided.

\section{Risk of bias findings}

The level 1 method (structured clinical interview) was used by $55 \%$ of the studies; $14 \%$ used the level 2 method (unstructured clinical interview); 15\% level 3 (standardized diagnostic questionnaire); $8 \%$ level 4 (unstandardized diagnostic questionnaire); $2 \%$ level 5 (non-diagnostic questionnaire); and $6 \%$ of studies used the level 6 method (self-report).

\section{Summary of sociodemographic findings}

See Table 2 for a summary of the findings from the 86 studies that reported on sociodemographic correlates of ED epidemiology. The most commonly studied correlates were age, sex, ethnicity, education level, socioeconomic status, urbanicity, and marital status. As can be seen, many null effects were observed; however, this may be expected due to studies that conducted multiple analyses for each ED diagnosis. Overall, EDs appear to be clearly associated with being female and younger overall. On a specific diagnostic level, however, this relationship was not so robust for BED, with most age-related effects being null. Less clear was an association between ED epidemiology and ethnicity, education, socioeconomic status, urbanicity, or marital status. The vast majority of ethnicity analyses were null, and of those analyses that found an effect, one ethnicity did not tend to dominate in its association with EDs. On a diagnostic level, however, BN tended to have a higher prevalence amongst minority ethnicities. An equal number of analyses found a significant association between lower and higher education level with ED epidemiology. Most analyses reported a null effect of socioeconomic status; however, of the six effects 
Table 3 Environmental correlates of eating disorder epidemiology

\begin{tabular}{|c|c|c|c|c|}
\hline Epidemiological correlate & n studies & $\begin{array}{l}n \text { analyses with } \\
\text { a null effect }\end{array}$ & $\begin{array}{l}n \text { analyses } \\
\text { with an effect }\end{array}$ & Effect(s) found \\
\hline Sporting environment & 21 & & & \\
\hline Sport & 14 & 27 & 6 & $\begin{array}{l}\text { Being an athlete (2); being a UK non-athlete versus } \\
\text { a Kenyan athlete (I); dancing (I); weight-lifting (I); } \\
\text { gym-user (I) }\end{array}$ \\
\hline Exercise load/level & 7 & 10 & 2 & $\begin{array}{l}\text { Lower exercise load (I); higher (competitive) } \\
\text { exercise level (I) }\end{array}$ \\
\hline Sport category & 6 & 4 & 7 & $\begin{array}{l}\text { Leanness sports (3); aesthetic sports ( } 3 \text { ); } \\
\text { anti-gravitation sports (I) }\end{array}$ \\
\hline Abuse & 14 & & & \\
\hline Sexual & 12 & 3 & 10 & Having been a victim of sexual abuse \\
\hline Physical & 7 & I & 7 & Having been a victim of physical abuse \\
\hline Partner violence & 2 & I & 2 & Having been abused by one's intimate partner \\
\hline Child abuse & 9 & & & \\
\hline Sexual & 8 & 13 & 9 & $\begin{array}{l}\text { Having been a victim of child sexual abuse (7); } \\
\text { having been a victim of child sexual abuse involving } \\
\text { intercourse (I); having been a victim of child sexual } \\
\text { abuse involving force or threats (I) }\end{array}$ \\
\hline Neglect & I & 0 & I & Having been a victim of child neglect \\
\hline Physical & I & 2 & 2 & Having been a victim of child physical abuse \\
\hline Psychological & I & 0 & I & Having been a victim of child psychological abuse \\
\hline Multiple & I & 0 & 1 & Having been a victim of multiple child abuse \\
\hline Physical or sexual & I & 0 & 3 & Having been a victim of either sexual or physical abuse \\
\hline Significant life events & 10 & & & \\
\hline Stress & 4 & 0 & 4 & $\begin{array}{l}\text { Having experienced major stressors, higher pressure, } \\
\text { or provoking agents }\end{array}$ \\
\hline Pregnancy & 3 & 2 & 2 & $\begin{array}{l}\text { Having ever been pregnant ( } I \text { ); been pregnant within } \\
\text { the past } 12 \text { months ( } I \text { ) }\end{array}$ \\
\hline Change family structure & 3 & 0 & 3 & Change in the family structure \\
\hline House moves & 3 & I & 2 & Moved house in the past 12 months \\
\hline Traumatic events & 2 & 2 & 0 & $\mathrm{~N} / \mathrm{A}$ \\
\hline Parental death & 2 & I & 0 & $\mathrm{~N} / \mathrm{A}$ \\
\hline Bereavement & 2 & I & I & Bereavement in the past 12 months \\
\hline End relationship & 2 & I & I & Ended intimate relationship in the past 12 months \\
\hline Significant positive events & I & I & 0 & $\mathrm{~N} / \mathrm{A}$ \\
\hline Bushfire exposure & I & I & 0 & $\mathrm{~N} / \mathrm{A}$ \\
\hline Abortion & I & I & 0 & $\mathrm{~N} / \mathrm{A}$ \\
\hline New relationship & I & I & 0 & N/A \\
\hline Military & 2 & & & \\
\hline Service branch & 2 & I & 3 & Marine Corps versus the Army, Navy, or Air Force \\
\hline Deployment status & I & 0 & 2 & $\begin{array}{l}\text { Deployed with combat exposure (I); deployed on } \\
\text { active duty (I) }\end{array}$ \\
\hline Number deployments & I & I & 0 & $\mathrm{~N} / \mathrm{A}$ \\
\hline Parental separation/absence & 3 & 2 & 0 & $\mathrm{~N} / \mathrm{A}$ \\
\hline Bullying & 2 & I & 2 & $\begin{array}{l}\text { Bullying victim (I); both a bullying victim and } \\
\text { perpetrator (I) }\end{array}$ \\
\hline Being in public/social/foster care & 2 & 2 & 0 & $\mathrm{n} / \mathrm{a}$ \\
\hline Modeling & 2 & 4 & 3 & Being a fashion model \\
\hline Seasonal bias & I & I & 0 & $\mathrm{~N} / \mathrm{A}$ \\
\hline Same/opposite sex twin & I & 4 & 0 & $\mathrm{~N} / \mathrm{A}$ \\
\hline
\end{tabular}

Abbreviation: N/A, not applicable.

found, four were for an association with lower socioeconomic status. In terms of the impact of urbanicity and marital status, the majority of effects were null.

Other sociodemographic correlates were less commonly studied and included parental variables (eg, parental marital status, parental education, and parental occupation), family composition variables (eg, number of siblings and birth order), timing of menarche or oigarche, sexual orientation, bullying, and migration status. Table 2 documents the effects found for these correlates; however, due to the small number 
of analyses conducted, there is less certainty of their association with ED epidemiology.

\section{Summary of the environmental findings}

Table 3 summarizes the findings from the 57 articles reporting on environmental correlates of ED epidemiology. Again, the number of null effects was high. The most frequently studied correlates pertained to the sporting environment and a history of sexual or physical abuse. The prevalence of EDs appeared to be higher in participants who engaged in particular types of sports, such as esthetic (eg, dancing and gymnastics) and leanness or weight-related (eg, wrestling) sports. Having ever been a victim of physical or sexual abuse was also associated with higher ED prevalence (particularly $\mathrm{BN}$ ), however less so was child sexual abuse per se, which had been assessed by a greater number of studies but returning mostly null effects. Modeling also appeared associated with a higher prevalence of both AN and subclinical AN but not other EDs. A number of significant life events were assessed as correlates of ED epidemiology. Having experienced significant stress in general (ie, reporting major stressors, higher pressure, or provoking agents) was associated with greater ED prevalence. Other events were less often studied; however, preliminary evidence may suggest an effect of disruptive events such as moving house and change in the family structure.

\section{Summary of the genetic findings}

Table 4 summarizes the findings from the 13 articles that reported on genetic correlates of ED epidemiology.
Three of these studies reported on the relationship of specific genes that are relevant to reward neurobiology and cerebral dopamine pathways or relevant to mood and other psychological features and cerebral serotonergic activity and to EDs. In one study, the short allele of the gene-linked polymorphic region of the serotonin transporter gene (5-HTTLPR) was found to be associated with bulimic EDs such as BN and BED but not with AN or EDNOS. The other two studies focused specifically on AN and BED, and found that the dopamine receptor D4 gene (DRD4) was associated with the binge/purge (but not the restrictive) subtype of $\mathrm{AN}$, and the dopamine receptor $\mathrm{D} 2$ gene (DRD2) was associated with BED. Relationships were complex, however, and in the latter study of Davis et $\mathrm{al}^{28}$ were contrary to hypothesis in that the DRD4 marker that is associated with reduced dopaminergic activity appeared to moderate greater reward sensitivity in participants with BED and obesity. The former study also found an association with the DRD4 gene and perfectionism in participants with and without a history of AN.

Six studies calculated heritability or genetic contribution estimates of AN, BN, and BED. Estimates ranged from: $22 \%$ to $76 \%$ for $\mathrm{AN}$ and broad AN (including participants who were missing one of the DSM-IV criteria); $52 \%$ to $62 \%$ for $\mathrm{BN}$ and broad $\mathrm{BN}$; and 57\% (N=1 study) for BED. Finally, one study assessed lifetime psychiatric morbidity in the relatives of participants with BED and found that most psychiatric disorders were significantly more prevalent in the relatives of BED participants compared with the relatives of controls.

Table 4 Genetic correlates of ED epidemiology

\begin{tabular}{|c|c|c|c|}
\hline $\begin{array}{l}\text { Epidemiological } \\
\text { correlate }\end{array}$ & $\begin{array}{l}\text { Studies } \\
\text { (n) }\end{array}$ & Significant effects & Null effects \\
\hline Genes & 3 & & \\
\hline 5-HTTLPR & I & $\begin{array}{l}\text { Associated with higher anxiety and bulimic pathology in } B N \text {, } \\
B E D \text {, and subclinical } B N \text { versus non-ED controls }\end{array}$ & $\begin{array}{l}\text { No effect in AN, EDNOS, or subclinical } \\
\text { AN }\end{array}$ \\
\hline DRD4 & I & Associated with $\mathrm{AN}$ and $\mathrm{AN}-\mathrm{BP}$ versus non-ED controls & No effect in AN-R \\
\hline DRD2 & I & $\begin{array}{l}\text { Associated with reward sensitivity in BED versus non-ED } \\
\text { controls }\end{array}$ & $\begin{array}{l}\text { No effect in comparison to obese } \\
\text { non-ED controls }\end{array}$ \\
\hline Heritability estimates & 6 & & \\
\hline AN & 2 & $22 \%(I) ; 48 \%(I)$ & $N / A$ \\
\hline $\mathrm{BN}$ & 4 & $55 \%(1) ; 61 \%(1) ; 62 \%(2)$ & $N / A$ \\
\hline BED & I & $57 \%$ & $\mathrm{~N} / \mathrm{A}$ \\
\hline Broad AN & 3 & $52 \%(I) ; 58 \%(I) ; 76 \%(I)$ & $\mathrm{N} / \mathrm{A}$ \\
\hline Broad BN & 2 & $52 \%(1) ; 60 \%(1)$ & $\mathrm{N} / \mathrm{A}$ \\
\hline $\begin{array}{l}\text { Psychiatric morbidity } \\
\text { in relatives }\end{array}$ & I & $\begin{array}{l}\text { More common in relatives of BED participants: AN, BED, any } \\
\text { ED, any depressive disorder, bipolar disorder, social phobia, } \\
\text { specific phobia, obsessive compulsive disorder, agoraphobia, panic } \\
\text { disorder, generalized anxiety disorder, and any anxiety disorder }\end{array}$ & $\begin{array}{l}\text { No effect of BN, EDNOS, major } \\
\text { depressive disorder, dysthymic disorder, } \\
\text { post-traumatic stress disorder, or any of } \\
\text { the substance use disorders }\end{array}$ \\
\hline
\end{tabular}

Abbreviations: 5-HTTLPR, short allele of the gene-linked polymorphic region of the serotonin transporter gene; AN, anorexia nervosa; BED, binge eating disorder; BN, bulimia nervosa; DRD2, the dopamine receptor D2 gene; DRD4, the dopamine receptor D4 gene; ED, eating disorder; EDNOS, EDs not otherwise specified; N/A, not available. 


\section{Discussion}

This review has summarized the findings from a large number of community-based studies published over the past three decades related to sociodemographic, environmental, and genetic correlates of ED epidemiology. Consistent with current thinking, ${ }^{1}$ we found fairly robust associations between ED prevalence and the female sex, younger age cohort, and a history of abuse, confirming what has been well established, and is also reflected in our treatment-seeking samples. An exception to this was BED, which did not appear as clearly associated with younger women; however, this supports a previous review of BED epidemiology, which found that in comparison to other EDs, BED is more common in older women and in men. ${ }^{29}$

On the other hand, we found little evidence of an association between EDs and ethnicity, socioeconomic status, education, or urbanicity. This flies against the stereotype of EDs as being a condition peculiar to wealthy, White, well educated women who live in major cities. ${ }^{30}$ Rather, of the effects that were found for socioeconomic status, the trend leaned toward those who were less wealthy. Further, far from White ethnicity being predominant in the epidemiology of EDs, of the 16 analyses that found an effect of ethnicity, ten implied that EDs were more common in minority groups, particularly BN.

This review provides a summary of correlates and not causal factors related to ED epidemiology. Thus, while factors highlighted in this review may be significantly related to EDs, we cannot be certain of the direction of this relationship. For instance, modeling and participation in esthetic sports (eg, dancing) were associated with a higher prevalence of EDs (particularly AN); but we do not know how much of the variation in this relationship is defined by characteristics of the modeling and dancing environments versus characteristics of the individual that influences both their likelihood to pursue such activities and their vulnerability to EDs. Likely, the answer is a reciprocal relationship whereby individual characteristics (such as perfectionism) interact with environmental pressures to result in the development of ED symptomatology (such as strict dieting and purging behavior).

In the same vein, the distinction made between sociodemographic and environmental correlates in this review was largely arbitrary, and was done with the aim to facilitate the reading of this paper. In reality, such distinctions are usually artificial, and considerable overlap and interactions exist between these categories and also with genetic influences. For example, in considering effects of ethnicity, one must assume that environmental influences such as cultural practices also make a contribution. Based on the assumption that sociodemographic, environmental, and genetic factors interact to influence ED development, ${ }^{31}$ we have not attempted to compare the relative influences of these factors as distinct entities on ED epidemiology. Suffice it to say that according to the heritability studies in this review, genetics may account for $50 \%-60 \%$ of the variability in EDs, leaving the remaining variability to be influenced by factors in the environment. Genetic influences are also being found to be associated with personality traits and risk factors for EDs, such as perfectionism, and may be important moderators of clinical features of the ED.

A strength, but also potentially a limitation, of this review was undoubtedly its large scope, which resulted in 149 articles to summarize. In future, it may be useful to conduct separate reviews for EDs (ie, for AN or BED), as correlates are expected to differ to some extent along diagnostic lines. It may have been a limitation to include articles over such a large time period (1985-2013), due to the change in diagnostic classification systems over time, which has seen slight changes to the criteria for $\mathrm{AN}$ and $\mathrm{BN}$, and the introduction of BED. However, while this undoubtedly influenced the prevalence estimates of EDs over time, it is less likely to have impacted on specific correlates. A preempted risk of bias for this review was variability in diagnostic assessment methods used across studies. However, when we assessed this risk, we found that $84 \%$ of the studies used either a structured/unstructured clinical interview or a standardized questionnaire designed to assess ED diagnosis; and 92\% used methods designed to align with the established diagnostic criteria within the DSM or ICD for EDs. Methods such as self-report or self-identification were rare. A further limitation was that data were extracted by one author only, and the search did not include "gray" literature. Finally, the generalizability of this review to males may be limited by the fact that many studies included female participants only, and on average, females constituted $79 \%$ of the study samples. It is hoped that with the growing recognition of male EDs, this will become less of a limitation in future reviews.

In summary, this review found that a number of factors influence ED epidemiology, most notably genetics, female sex, younger age, participation in esthetic/leanness sports, and having been a victim of sexual or physical abuse. Importantly, we also found a number of factors unlikely to influence variability in ED epidemiology, for instance ethnicity, educational attainment, socioeconomic status, urbanicity, and participating in general sports. Other factors that may be 
potentially related to EDs are in need of further exploration in community-based studies, for example bullying, sexual orientation, and other specific disruptive life events. While genetic research is slowly gaining traction in the ED field, it is advisable that these studies move beyond clinical samples in order to increase the applicability of findings to the broader ED population.

\section{Disclosure}

The authors report no conflicts of interest in this work.

\section{References}

1. American Psychiatric Association. Diagnostic and Statistical Manual for Mental Disorders, Fifth Edition (DSM-5). Washington DC: American Psychiatric Association; 2013.

2. Jenkins PE, Hoste RR, Meyer C, Blissett JM. Eating disorders and quality of life: a review of the literature. Clin Psychol Rev. 2011;31(1): 113-121.

3. Krauth C, Buser K, Vogel H. How high are the costs of eating disorders anorexia nervosa and bulimia nervosa - for German society? Eur $J$ Health Econ. 2002;3(4):244-250.

4. Waraich P, Goldner EM, Somers JM, Hsu L. Prevalence and incidence studies of mood disorders: a systematic review of the literature. Can J Psychiatry. 2004;49(2):124-138.

5. Baxter AJ, Scott KM, Vos T, Whiteford HA. Global prevalence of anxiety disorders: a systematic review and meta-regression. Psychol Med. 2013;43(5):897-910.

6. Kirkbride JB, Errazuriz A, Croudace TJ, et al. Incidence of schizophrenia and other psychoses in England, 1950-2009: a systematic review and meta-analyses. PLoS One. 2012;7(3):e31660.

7. Australian Bureau of Statistics [homepage on the Internet]. Australian Bureau of Statistics; 2007 [updated October 23, 2008]. 4326.0 National Survey of Mental Health and Wellbeing: summary of results, 2007. Available from: http://www.abs.gov.au/ausstats/abs@.nsf/ $\mathrm{mf} / 4326.0$. Accessed November 16, 2013.

8. Hoek HW. Incidence, prevalence and mortality of anorexia nervosa and other eating disorders. Curr Opin Psychiatry. 2006;19(4):389-394.

9. World Health Organization. The ICD-10 Classification of Mental and Behavioral Disorders: Clinical Descriptions and Diagnostic Guidelines. Geneva: World Health Organization; 2011 [cited March 19, 2011]; Available from: http://www.who.int/classifications/icd/en/ bluebook.pdf. Accessed December 6, 2013.

10. Cachelin FM, Striegel-Moore RH. Help seeking and barriers to treatment in a community sample of Mexican American and European American women with eating disorders. Int J Eat Disord. 2006;39(2): 154-161.

11. Mond JM, Hay PJ, Rodgers B, Owen C. Health service utilization for eating disorders: findings from a community-based study. Int $J$ Eat Disord. 2007;40:399-408.

12. Hart LM, Granillo MT, Jorm AF, Paxton SJ. Unmet need for treatment in the eating disorders: a systematic review of eating disorder specific treatment seeking among community cases. Clin Psychol Rev. 2011;31: 727-735.

Clinical Epidemiology

\section{Publish your work in this journal}

Clinical Epidemiology is an international, peer-reviewed, open access journal focusing on disease and drug epidemiology, identification of risk factors and screening procedures to develop optimal preventative initiatives and programs. Specific topics include: diagnosis, prognosis, treatment, screening, prevention, risk factor modification, systematic
13. Mond JM, Hay PJ, Darby A, et al. Women with bulimic eating disorders: When do they receive treatment for an eating problem? J Consult Clin Psychol. 2009;77(5):835-844.

14. Mitchison D, Mond J, Slewa-Younan S, Hay P. The prevalence and impact of eating disorder behaviours in Australian men. $J$ Eating Disorders. 2013;1(Suppl 1):O23.

15. Mond JM, Hay PJ. Functional impairment associated with bulimic behaviors in a community sample of men and women. Int J Eat Disord. 2007;40:391-398.

16. Striegel-Moore RH, Rosselli F, Perrin N, et al. Gender difference in the prevalence of eating disorder symptoms. Int J Eat Disord. 2009;42: 471-474.

17. Hay PJ, Mond J, Buttner P, Darby A. Eating disorder behaviors are increasing: findings from two sequential community surveys in South Australia. PLoS One. 2008;3(2):e1541.

18. Cachelin F, Barzegarnazari E, Striegel-Moore R. Disordered eating, acculturation, and treatment-seeking in a community sample of Hispanic, Asian, Black, and White women. Psychol Women $Q$. 2000;24:244-253.

19. Hay P, Carriage C. Eating disorder features in indigenous Aboriginal and Torres Strait Islander Australian Peoples. BMC Public Health. 2012;12:233.

20. Mashhadi A, Noordenbos G. Dieting and the development of eating disorders among Iranian women: comparing the risk between Tehran and The Netherlands. Food Cult Soc. 2012;15(1):43-60.

21. Miller M, Pumariega A. Culture and eating disorders: a historical and cross-cultural review. Psychiatry. 2001;64(2):93-110.

22. Moher D, Liberati A, Tetzlaff J, Altman DG; PRISMA Group. Preferred reporting items for systematic reviews and meta-analyses: the PRISMA statement. PLoS Med. 2009;6(7):e1000097.

23. Welch $\mathrm{G}$, Hall $\mathrm{A}$. Is the prevalence of bulimia nervosa higher among tertiary education populations? N Z Med J. 1990;103(899):476-477.

24. Fairburn CG, Cooper Z. The Eating Disorder Examination. 12th ed. In: Fairburn CG, Wilson G, editors. Binge Eating: Nature, Assessment and Treatment. New York: Guildford Press; 1993.

25. First MB, Gibbon M. The Structured Clinical Interview for DSM-IV Axis I Disorders (SCID-I) and the Structured Clinical Interview for DSM-IV Axis II Disorders (SCID-II). In: Hilsenroth MJ, Segal DL, editors. Comprehensive Handbook of Psychological Assessment: Personality Assessment. Hoboken, NJ: John Wiley \& Sons; 2004;2:134-143.

26. Ghaderi A, Scott B. The preliminary reliability and validity of the Survey for Eating Disorders (SEDs): a self-report questionnaire for diagnosing eating disorders. Eur Eating Disord Rev. 2002;10(1):61-76.

27. Fairburn CG. Eating Disorder Examination Questionnaire. In: Cognitive Behaviour Therapy and Eating Disorders. New York: Guilford Press; 2008.

28. Davis C, Levitan RD, Kaplan AS, et al. Reward sensitivity and the D2 dopamine receptor gene: A case-control study of binge eating disorder Prog Neuropsychopharmacol Biol Psychiatry. 2008;32(3):620-628.

29. Striegel-Moore RH, Franko DL. Epidemiology of binge eating disorder. Int J Eat Disord. 2003;34(S1):S19-S29.

30. Bruch H. The Golden Cage: The Enigma of Anorexia Nervosa. New York: Vintage Books; 1979.

31. Campbell IC, Mill J, Uher R, Schmidt U. Eating disorders, geneenvironment interactions and epigenetics. Neurosci Biobehav Rev 2011;35(3):784-793.

\section{Dovepress}

reviews, risk \& safety of medical interventions, epidemiology \& biostatical methods, evaluation of guidelines, translational medicine, health policies \& economic evaluations. The manuscript management system is completely online and includes a very quick and fair peer-review system, which is all easy to use. 